\title{
Structures and stability of calcium and magnesium carbonates at mantle pressures
}

\author{
Chris J. Pickard* \\ Department of Physics $\& 3$ Astronomy, University College London, Gower Street, London WC1E 6BT, UK \\ London Institute for Mathematical Sciences, 35a South Street, Mayfair, London, W1K 2XF, UK \\ Richard J. Needs \\ Theory of Condensed Matter Group, Cavendish Laboratory, \\ J J Thomson Avenue, Cambridge CB3 OHE, UK
}

(Dated: April 29, 2015)

\begin{abstract}
$A b$ initio random structure searching (AIRSS) and density functional theory methods are used to predict structures of calcium and magnesium carbonate $\left(\mathrm{CaCO}_{3}\right.$ and $\left.\mathrm{MgCO}_{3}\right)$ at high pressures. We find a previously unknown $\mathrm{CaCO}_{3}$ structure which is more stable than the aragonite and "post aragonite" phases in the range 32-48 GPa. At pressures from $76 \mathrm{GPa}$ to well over $100 \mathrm{GPa}$ the most stable phase is a previously unknown $\mathrm{CaCO}_{3}$ structure of the pyroxene type with fourfold coordinated carbon atoms. We also predict a stable structure of $\mathrm{MgCO}_{3}$ in the range 85-101 GPa. Our results lead to a revision of the phase diagram of $\mathrm{CaCO}_{3}$ over more than half the pressure range encountered within the Earth's mantle, and smaller changes to the phase diagram of $\mathrm{MgCO}_{3}$. We predict $\mathrm{CaCO}_{3}$ to be more stable than $\mathrm{MgCO}_{3}$ in the Earth's mantle above $100 \mathrm{GPa}$, and that $\mathrm{CO}_{2}$ is not a thermodynamically stable compound under deep mantle conditions. Our results have significant implications for understanding the Earth's deep carbon cycle.
\end{abstract}

PACS numbers: 64.70.K-, 71.15.Mb, 61.50.Ks, 62.50.-p

\section{INTRODUCTION}

The occurrence of $\mathrm{CO}_{2}$ within magmas and volcanic gases indicates a significant carbon presence within the Earth's lower mantle $e^{1,2}$. Carbon has a low solubility in mantle silicates and the majority of the oxidized carbon in the Earth's mantle is believed to exist in the form of carbonates. Calcium and magnesium carbonate $\left(\mathrm{CaCO}_{3}\right.$ and $\left.\mathrm{MgCO}_{3}\right)$ are the main sources and sinks of atmospheric $\mathrm{CO}_{2}$ within the Earth's mantle. Carbonates are conveyed into the deep Earth by subduction, and carbon is recycled to the surface via volcanic processes in the form of $\mathrm{CO}_{2}$-containing fluids and solids, and diamonds ${ }^{3,4}$. However, the details of carbon storage within the Earth's interior are unclear. The Deep Carbon Observatory ${ }^{5}$ has been set up to investigate carbon within the Earth's deep interior. $\mathrm{CaCO}_{3}$ and $\mathrm{MgCO}_{3}$ play fundamental roles in the global carbon cycle and influence the climate of our planet ${ }^{6,7}$. Knowledge of the structures, energetics and other properties of $\mathrm{CaCO}_{3}$ and $\mathrm{MgCO}_{3}$ at high pressures is therefore important in understanding the Earth's mantle, and especially the carbon cycle.

The low-pressure calcite form ${ }^{8}$ of $\mathrm{CaCO}_{3}$ is one of the most abundant minerals on the Earth's surface and is the main constituent of metamorphic marbles. Several metastable calcite-like phases have been observed ${ }^{9-11}$, and a calcite-related phase has been reported at around $25 \mathrm{GPa}^{11,12}$. At pressures of about $2 \mathrm{GPa}$ calcite transforms to the aragonite structure ${ }^{13}$ of Pnma symmetry. At about $40 \mathrm{GPa}$ aragonite transforms into the "post aragonite" (Pmmn) structure of $\mathrm{CaCO}_{3}$, which is stable up to at least $86 \mathrm{GPa}^{14,15}$. The low pressure magnesite phase of $\mathrm{MgCO}_{3}$ has the same structure as calcite.
Experiments indicate that magnesite is stable up to 80 $\mathrm{GPa}^{16}$, and a phase transition occurs above $100 \mathrm{GPa}$ to an unknown magnesite II structure ${ }^{17,18}$.

\section{STRUCTURE SEARCHES}

Density functional theory (DFT) calculations for high pressure phases of $\mathrm{CaCO}_{3}$ and $\mathrm{MgCO}_{3}$ were performed by Oganov et al. using an evolutionary structure searching algorithm ${ }^{15,19}$. These calculations predicted a transition from the calcite to aragonite to "post aragonite" structures of $\mathrm{CaCO}_{3}$, followed by a transition to a structure of $C 222_{1}$ symmetry at pressures over $100 \mathrm{GPa}$. Similar calculations for $\mathrm{MgCO}_{3}$ predicted transitions from magnesite to a structure of $C 2 / m$ symmetry at $82 \mathrm{GPa}$, followed by a transition to a structure of $P 2_{1}$ symmetry at $138 \mathrm{GPa}$, and a phase of $P n a 2_{1}$ symmetry at 160 $\mathrm{GPa}^{19}$.

Calculations using the $a b$ initio random structure searching (AIRSS) technique ${ }^{20}$ have led to the discovery of structures that have subsequently been verified by experiment, for example, in silane ${ }^{21}$, aluminium hydride ${ }^{22}$, ammonia monohydrate $^{23}$ and ammonia dihydrate ${ }^{24}$. In the basic AIRSS approach a cell volume and shape is selected at random from within reasonable ranges, the atoms are added at random positions, and the system is relaxed until the forces on the atoms are negligible and the pressure takes the required value. This procedure is repeated many times, leading to a reasonably unbiased scheme which allows a significant portion of the "structure space" to be investigated, although the sampling may be rather sparse. This approach is often successful for small systems, but it involves sampling a large portion 
of the high-energy structure space which is not normally of interest. We therefore reduce the size of the structure space investigated by constraining the searches.

We first perform searches in small cells, constraining the initial structures so that all of the atoms are at least $1 \AA$ apart. The low-enthalpy structures obtained from these calculations give us information about the favorable bonding configurations and likely nearest neighbor distances between the different atomic types. At low pressures we find that the low-enthalpy structures contain well-defined triangular $\mathrm{CO}_{3}$ or ring $\mathrm{C}_{3} \mathrm{O}_{9}$ units, and therefore we place these units and $\mathrm{Ca}$ or $\mathrm{Mg}$ atoms randomly within the cells of random shapes. We ensure that the atoms are not too close together by constraining the initial values of the minimum distances between atoms for each of the six possible pairs of atomic species. The six minimum distances are obtained from low-enthalpy structures found in the small-cell searches. To construct the initial structures at higher pressures we use minimum distances from low-enthalpy small-cell structures to prepare new larger structures that approximately satisfy the minimum distance constraints. This approach helps to space out the different species appropriately, while retaining a high degree of randomness. We perform searches at both low and high pressures, using structures which are constrained to have a certain symmetry which is enforced during the relaxation, but are otherwise random ${ }^{20}$. This approach is useful because low energy structures often possess symmetry ${ }^{25,26}$, although symmetry constraints break up the allowed structure space into disconnected regions and can prevent some structures from relaxing to lower energy ones ${ }^{20}$. We consider structures containing up to eight formula units (f.u.) for $\mathrm{CaCO}_{3}$ and twelve f.u. for $\mathrm{MgCO}_{3}$.

Our first-principles DFT calculations are performed using the default CASTEP 7.0 on-the-fly ultrasoft pseudopotentials $^{29}$, and a plane-wave basis set energy cutoff of $640 \mathrm{eV}^{27}$. We use the Perdew-Burke-Ernzerhof (PBE) generalized gradient approximation (GGA) density functional ${ }^{28}$. We use a Brillouin zone sampling grid of spacing $2 \pi \times 0.1 \AA^{-1}$ for the searches, and a finer spacing of $2 \pi \times 0.05 \AA^{-1}$ for the final results reported in this paper. We perform static lattice calculations and vibrational effects are not included.

\section{III. $\mathrm{CaCO}_{3}$, PRESSURE $\leq 50$ GPA}

Calculated enthalpy-pressure curves for $\mathrm{CaCO}_{3}$ phases are shown in Fig. 1, relative to the enthalpy of the "post aragonite" phase. The transition from aragonite to "post aragonite" becomes energetically favorable at about 42 GPa, in agreement with previous DFT results ${ }^{15,19,30,31}$ and experiment ${ }^{14}$. We performed calculations for the $\mathrm{CaCO}_{3}$-VI structure reported in Ref. 11, which was suggested as a possible high pressure phase of $\mathrm{CaCO}_{3}$. However, we found it to be very high in enthalpy, with a strongly anisotropic stress and large forces on the atoms.

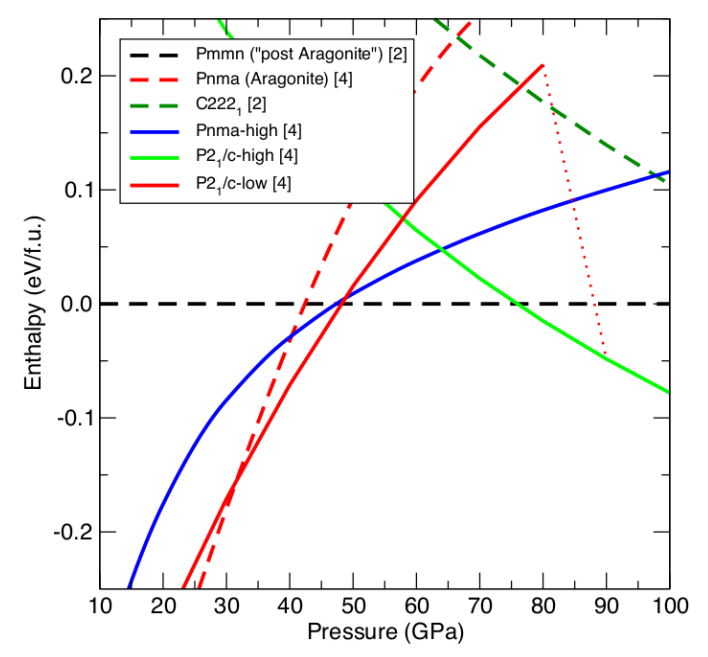

FIG. 1. (Color online) Enthalpies per f.u. of $\mathrm{CaCO}_{3}$ phases relative to "post aragonite", with the number of f.u. per primitive unit cell given within square brackets. The enthalpies of phases known prior to the current study are shown as dashed lines, while those found in the current study are shown as solid lines. The dotted red line shows the collapse of the $\mathrm{CaCO}_{3}$ $P 2_{1} / c-l$ structure into the more stable $\mathrm{CaCO}_{3}-P 2_{1} / c-h$ structure at $80-90 \mathrm{GPa}$.

Relaxation of the $\mathrm{CaCO}_{3}$-VI structure at $40 \mathrm{GPa}$ led to a reasonably stable structure with an enthalpy close to that of aragonite, but the relaxed structure does not have a region of stability on our phase diagram (Fig. 1). We also found a structure of Pnma symmetry ("CaCO${ }_{3}-P n m a-$ $h$ ", where $h$ denotes "high pressure") that is predicted to be more stable than aragonite above $40 \mathrm{GPa}$, and more stable than "post aragonite" below $47 \mathrm{GPa}$. However, $\mathrm{CaCO}_{3}-P n m a-h$ does not have a region of thermodynamic stability on our phase diagram because we find a previously unknown structure of $P 2_{1} / c$ symmetry ("CaCO $\mathrm{Ca}_{3}-P 2_{1} / c-l$ ", where $l$ denotes "low pressure") which is calculated to be the most stable phase in the pressure range 32-48 GPa, see Fig. 1 and Table I.

At $42 \mathrm{GPa} \mathrm{CaCO}_{3}-P 2_{1} / c$ - $l$ is calculated to be about $0.05 \mathrm{eV}$ per f.u. more stable than aragonite and "post aragonite" and, because these $s p^{2}$ bonded structures are similar, we expect that DFT calculations should give rather accurate enthalpy differences between them. However, our $\mathrm{CaCO}_{3}-P 2_{1} / c-l$ and $\mathrm{CaCO}_{3}-P n m a-h$ structures do not provide as good a fit to the experimental X-ray diffraction data as the "post aragonite" phase ${ }^{15}$. It is possible that large energy barriers hinder formation of the $\mathrm{CaCO}_{3}-P 2_{1} / c$ - $l$ structure. Another possibility is that the laser-heated sample melts and the least stable polymorph crystallizes from the melt first, in analogy to "Ostwald's rule" 32 . In any case, the conditions within the Earth's mantle are not the same as in diamond anvil cell experiments, and the timescales associated with geological processes are enormously longer than those for laboratory experiments. 
TABLE I. $\mathrm{CaCO}_{3}$ structures introduced in the current manuscript. The structures are also provided in the Supplemental Material ${ }^{33}$ in the form of .cif files.

\begin{tabular}{|c|c|c|c|c|c|c|c|c|c|}
\hline \multirow{2}{*}{$\begin{array}{l}\text { Pressure } \\
(\mathrm{GPa})\end{array}$} & \multirow{2}{*}{$\begin{array}{l}\text { Space group } \\
\text { (and label) }\end{array}$} & \multirow{2}{*}{\multicolumn{3}{|c|}{$\begin{array}{l}\text { Lattice parameters } \\
\qquad(\AA, \text { deg. })\end{array}$}} & \multicolumn{5}{|c|}{ Atomic coordinates } \\
\hline & & & & & Species & $x$ & $y$ & $z$ & Wyckoff site \\
\hline \multirow[t]{5}{*}{60} & $P 2_{1} / c-1$ & $a=4.653$ & $b=3.350$ & $c=12.024$ & Ca1 & 0.9025 & 0.3054 & 0.1004 & $4 \mathrm{e}$ \\
\hline & & $\alpha=90.0$ & $\beta=123.328$ & $\gamma=90.0$ & $\mathrm{C} 1$ & 0.5353 & 0.4420 & 0.3580 & $4 \mathrm{e}$ \\
\hline & & & & & O1 & 0.2428 & 0.3026 & 0.3197 & $4 e$ \\
\hline & & & & & $\mathrm{O} 2$ & 0.7285 & 0.2967 & 0.3263 & $4 \mathrm{e}$ \\
\hline & & & & & O3 & 0.6603 & 0.7176 & 0.4483 & $4 \mathrm{e}$ \\
\hline \multirow[t]{5}{*}{60} & $P 2_{1} / c-h$ & $a=4.755$ & $b=3.430$ & $c=9.540$ & $\mathrm{Ca} 1$ & 0.3228 & 0.1984 & 0.0874 & $4 \mathrm{e}$ \\
\hline & & $\alpha=90.0$ & $\beta=106.466$ & $\gamma=90.0$ & $\mathrm{C} 1$ & 0.8539 & 0.4897 & 0.1767 & $4 \mathrm{e}$ \\
\hline & & & & & O1 & 0.6148 & 0.6909 & 0.1704 & $4 e$ \\
\hline & & & & & $\mathrm{O} 2$ & 0.8358 & 0.2893 & 0.0571 & $4 \mathrm{e}$ \\
\hline & & & & & $\mathrm{O} 3$ & 0.8987 & 0.2365 & 0.3004 & $4 \mathrm{e}$ \\
\hline \multirow[t]{4}{*}{60} & Pnma-h & $a=3.981$ & $b=4.545$ & $c=8.501$ & Ca1 & 0.3817 & 0.2500 & 0.1189 & $4 \mathrm{c}$ \\
\hline & & $\alpha=90.0$ & $\beta=90.0$ & $\gamma=90.0$ & $\mathrm{C} 1$ & 0.5273 & 0.7500 & 0.3695 & $4 c$ \\
\hline & & & & & O1 & 0.3803 & 0.5042 & 0.3562 & $8 \mathrm{~d}$ \\
\hline & & & & & $\mathrm{O} 2$ & 0.8373 & 0.7500 & 0.4042 & $4 c$ \\
\hline
\end{tabular}

\section{IV. $\mathrm{CaCO}_{3}$, PRESSURE $>50$ GPA}

At higher pressures we find another $\mathrm{CaCO}_{3}$ structure of $P 2_{1} / c$ symmetry ("CaCO${ }_{3}-P 2_{1} / c-h$ ") to be stable from $76 \mathrm{GPa}$ to well above $100 \mathrm{GPa}$. Our $\mathrm{CaCO}_{3}-P 2_{1} / c$ $h$ structure is about $0.18 \mathrm{eV}$ per f.u. more stable than the $C 222_{1}$ structure found by Oganov et $a l .{ }^{15}$, see Fig. 1 , and $C 222_{1}$ does not have a region of thermodynamic stability. We also find that at about 80-90 $\mathrm{GPa} \mathrm{CaCO}_{3}-$ $P 2_{1} / c-l$ transforms into the more stable $\mathrm{CaCO}_{3}-P 2_{1} / c-h$ structure without any apparent energy barrier (dotted red line in Fig. 1). Our calculations lead to the prediction of a new and more stable polymorph of $\mathrm{CaCO}_{3}$ at pressures $>76 \mathrm{GPa}$.

\section{V. $\mathrm{MgCO}_{3}$}

Calculated enthalpy-pressure curves for $\mathrm{MgCO}_{3}$ phases in the pressure range 50-200 GPa are shown in Fig. 2, relative to the $C 2 / m$ phase. We find a previously unreported structure of $P \overline{1}$ symmetry to be the most stable in the range 85-101 GPa. We also find a phase of $P 2_{1} 2_{1} 2_{1}$ symmetry that is marginally the most stable at pressures around $144 \mathrm{GPa}$, see Fig. 2 and Table II.

\section{STRUCTURES AND BONDING}

The carbon atoms in the calcite, aragonite, "post aragonite", and our $\mathrm{CaCO}_{3}-P 2_{1} / c-l$ and $\mathrm{CaCO}_{3}-P n m a-h$ structures contain threefold coordinated carbon atoms, as does the magnesite phase of $\mathrm{MgCO}_{3}$. These structures contain triangular $\mathrm{CO}_{3}^{2-}$ ions with $s p^{2}$ bonding. In aragonite and "post aragonite" the $\mathrm{CO}_{3}^{2-}$ ions are coplanar, but in our $\mathrm{CaCO}_{3}-\mathrm{Pnma-h}$ structure they are somewhat tilted, while in $\mathrm{CaCO}_{3}-P 2_{1} / c-l$ they are tilted at approx-

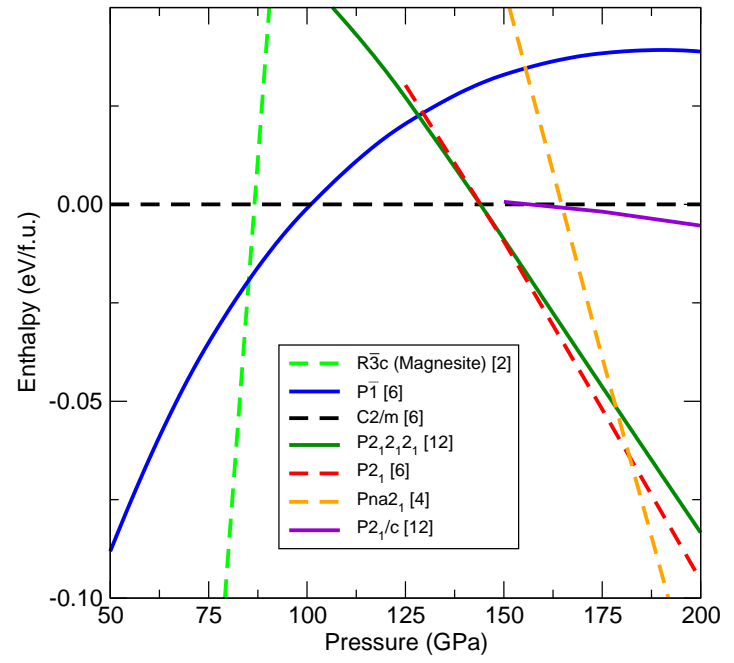

FIG. 2. (Color online) Enthalpies per f.u. of $\mathrm{MgCO}_{3}$ phases relative to the $C 2 / m$ phase, with the number of f.u. per primitive unit cell given within square brackets. Previously known phases are shown as dashed lines, and those found in the current study are shown as solid lines.

imately $90^{\circ}$ to one another, see Fig. 3. More details of the structures are given in the Supplemental Material ${ }^{33}$.

The high-pressure $\mathrm{CaCO}_{3}-P 2_{1} / c$ - $h$ and $C 222_{1}$ structures contain fourfold coordinated carbon atoms and are of the pyroxene type. $\mathrm{CaCO}_{3}-P 2_{1} / c-h$ and $C 222_{1}$ possess very similar calcium lattices but the packing of the pyroxene chains is different, as can be seen in Fig. 4. In $C 222_{1}$ each of the chains is orientated in the same manner, but $\mathrm{CaCO}_{3}-P 2_{1} / c$ - $h$ alternate chains run in the reverse direction, see Fig. 4, and consequently the unit cell of $\mathrm{CaCO}_{3}-P 2_{1} / c$ - $h$ contains four f.u., whereas $C 222_{1}$ contains two. When viewed along the axis of the chains, the $\mathrm{CaCO}_{3}-P 2_{1} / c-h$ and $C 222_{1}$ structures appear almost 
TABLE II. $\mathrm{MgCO}_{3}$ structures introduced in the current manuscript. The structures are also provided in the Supplemental Material $^{33}$ in the form of .cif files.

\begin{tabular}{|c|c|c|c|c|c|c|c|c|c|}
\hline \multirow{2}{*}{$\begin{array}{l}\text { Pressure } \\
(\mathrm{GPa})\end{array}$} & \multirow[t]{2}{*}{ Space group } & \multirow{2}{*}{\multicolumn{3}{|c|}{$\begin{array}{l}\text { Lattice parameters } \\
(\AA, \text { deg. })\end{array}$}} & \multicolumn{5}{|c|}{ Atomic coordinates } \\
\hline & & & & & Species & $x$ & $y$ & $z$ & Wyckoff site \\
\hline \multirow[t]{15}{*}{100} & $P 1$ & $a=5.211$ & $b=5.238$ & $c=7.268$ & Mg1 & 0.7402 & 0.2550 & 0.0018 & $2 \mathrm{i}$ \\
\hline & & $\alpha=70.030$ & $\beta=81.904$ & $\gamma=78.272$ & Mg2 & 0.5684 & 0.4665 & 0.3166 & $2 \mathrm{i}$ \\
\hline & & & & & Mg3 & 0.0668 & 0.1821 & 0.6483 & $2 \mathrm{i}$ \\
\hline & & & & & $\mathrm{C} 1$ & 0.2230 & 0.2096 & 0.0270 & $2 \mathrm{i}$ \\
\hline & & & & & $\mathrm{C} 2$ & 0.0831 & 0.3355 & 0.3077 & $2 \mathrm{i}$ \\
\hline & & & & & C3 & 0.4392 & -0.0215 & 0.3206 & $2 \mathrm{i}$ \\
\hline & & & & & $\mathrm{O} 1$ & 0.1249 & 0.1529 & -0.1044 & $2 \mathrm{i}$ \\
\hline & & & & & $\mathrm{O} 2$ & 0.0090 & 0.2939 & 0.1457 & $2 \mathrm{i}$ \\
\hline & & & & & O3 & -0.1180 & 0.3895 & 0.4213 & $2 \mathrm{i}$ \\
\hline & & & & & $\mathrm{O} 4$ & 0.3440 & -0.0410 & 0.1523 & $2 \mathrm{i}$ \\
\hline & & & & & O5 & 0.3749 & 0.3877 & -0.0402 & $2 \mathrm{i}$ \\
\hline & & & & & O6 & 0.2039 & 0.0684 & 0.4143 & $2 \mathrm{i}$ \\
\hline & & & & & $\mathrm{O} 7$ & 0.2277 & 0.5237 & 0.2623 & $2 \mathrm{i}$ \\
\hline & & & & & O8 & 0.5430 & -0.2611 & 0.4243 & $2 \mathrm{i}$ \\
\hline & & & & & O9 & 0.6108 & 0.1413 & 0.2683 & $2 \mathrm{i}$ \\
\hline \multirow[t]{15}{*}{200} & $P 2_{1} / c$ & $a=6.620$ & $b=6.191$ & $c=7.805$ & Mg1 & 0.2995 & 0.0071 & 0.3154 & $4 \mathrm{e}$ \\
\hline & & $\alpha=90.0$ & $\beta=76.370$ & $\gamma=90.0$ & Mg2 & 0.3387 & 0.5069 & 0.4226 & $4 \mathrm{e}$ \\
\hline & & & & & Mg3 & 0.0072 & 0.2485 & 0.5010 & $4 \mathrm{e}$ \\
\hline & & & & & C1 & 0.3376 & 0.3267 & 0.1292 & $4 \mathrm{e}$ \\
\hline & & & & & $\mathrm{C} 2$ & 0.3258 & 0.6887 & 0.1223 & $4 \mathrm{e}$ \\
\hline & & & & & C3 & 0.0377 & 0.5030 & 0.2680 & $4 \mathrm{e}$ \\
\hline & & & & & $\mathrm{O} 1$ & 0.4526 & 0.1914 & 0.1703 & $4 \mathrm{e}$ \\
\hline & & & & & $\mathrm{O} 2$ & 0.4330 & 0.5138 & 0.1447 & $4 \mathrm{e}$ \\
\hline & & & & & O3 & 0.4206 & 0.8618 & 0.1263 & $4 \mathrm{e}$ \\
\hline & & & & & $\mathrm{O} 4$ & 0.1605 & 0.6776 & 0.2741 & $4 \mathrm{e}$ \\
\hline & & & & & $\mathrm{O} 5$ & 0.1622 & 0.3320 & 0.2746 & $4 \mathrm{e}$ \\
\hline & & & & & O6 & 0.2567 & 0.6791 & -0.0120 & $4 \mathrm{e}$ \\
\hline & & & & & $\mathrm{O} 7$ & 0.2789 & 0.2997 & -0.0107 & $4 \mathrm{e}$ \\
\hline & & & & & O8 & -0.0248 & 0.5014 & 0.1312 & $4 \mathrm{e}$ \\
\hline & & & & & O9 & -0.1068 & 0.5009 & 0.4078 & $4 \mathrm{e}$ \\
\hline \multirow[t]{15}{*}{200} & $P 2_{1} 2_{1} 2_{1}$ & $a=9.436$ & $b=7.505$ & $c=4.355$ & $\operatorname{Mg} 1$ & 0.3844 & 0.0866 & 0.6677 & $4 a$ \\
\hline & & $\alpha=90.0$ & $\beta=90.0$ & $\gamma=90.0$ & Mg2 & 0.3853 & 0.4322 & 0.5954 & $4 a$ \\
\hline & & & & & Mg3 & 0.7175 & 0.2426 & 0.8525 & $4 a$ \\
\hline & & & & & $\mathrm{C} 1$ & 0.6365 & 0.1079 & 0.3554 & $4 a$ \\
\hline & & & & & $\mathrm{C} 2$ & 0.6378 & 0.4092 & 0.4146 & $4 a$ \\
\hline & & & & & C3 & 0.4693 & 0.2745 & 0.1320 & $4 \mathrm{a}$ \\
\hline & & & & & $\mathrm{O} 1$ & 0.7155 & 0.2615 & 0.3550 & $4 \mathrm{a}$ \\
\hline & & & & & $\mathrm{O} 2$ & 0.5754 & 0.0976 & 0.6061 & $4 a$ \\
\hline & & & & & $\mathrm{O} 3$ & 0.7249 & 0.5364 & 0.4483 & $4 a$ \\
\hline & & & & & $\mathrm{O} 4$ & 0.5697 & 0.3804 & 0.6620 & $4 a$ \\
\hline & & & & & $\mathrm{O} 5$ & 0.5526 & 0.4243 & 0.1699 & $4 a$ \\
\hline & & & & & O6 & 0.6038 & 0.7354 & 0.1361 & $4 a$ \\
\hline & & & & & $\mathrm{O} 7$ & 0.7172 & -0.0162 & 0.2647 & $4 a$ \\
\hline & & & & & O8 & 0.5613 & 0.1411 & 0.0859 & $4 \mathrm{a}$ \\
\hline & & & & & O9 & 0.3890 & 0.2872 & -0.0924 & $4 a$ \\
\hline
\end{tabular}

identical. $\mathrm{CaCO}_{3}-P 2_{1} / c$ - $h$ and $C 222_{1}$ have very similar volumes at high pressures, with $C 222_{1}$ being slightly denser, which leads to almost parallel enthalpy-pressure relations, see Fig. 1. The lower enthalpy of $\mathrm{CaCO}_{3}-$ $P 2_{1} / c$ - $h$ must therefore arise from more favorable electrostatic interactions between the pyroxene chains.

\section{A. High-pressure X-ray data for $\mathrm{CaCO}_{3}$}

Ono et $a l .{ }^{34}$ performed laser-heated diamond anvil cell experiments on $\mathrm{CaCO}_{3}$ at $182 \mathrm{GPa}$. X-ray diffraction data for the $C 222_{1}{ }^{15}$ and $\mathrm{CaCO}_{3}-P 2_{1} / c$ - $h$ structures are compared in Fig. 5 with the experimental data from Fig. 1 of Ref. 34. Note the appearance of three peaks marked with stars in the experimental data that arise from the 

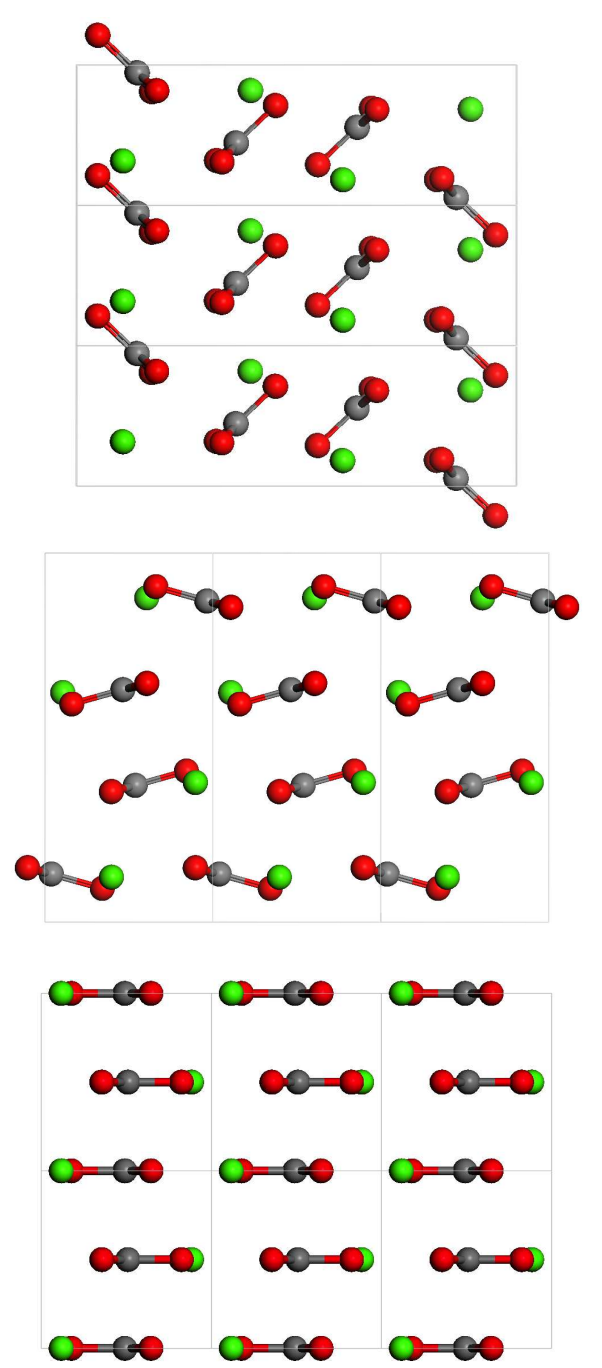

FIG. 3. (Color online) The $\mathrm{CaCO}_{3}-P 2_{1} / c-l$ (top), $\mathrm{CaCO}_{3}$ Pnma- $h$ (middle), and "post aragonite" (bottom) structures of $\mathrm{CaCO}_{3}$ at $40 \mathrm{GPa}$. The $\mathrm{Ca}$ atoms are in green, the carbon in grey, and the oxygen in red.

platinum used to enhance heat absorption during the laser heating and as a pressure calibrant. The experimental data is not of very high resolution. The diffraction patterns of the theoretical $C 222_{1}$ and $\mathrm{CaCO}_{3}-P 2_{1} / c-h$ structures share many common features. There are also clear similarities between the theoretical and experimental X-ray data, but the experimental data is of insufficient resolution to allow the structure to be determined unambiguously. We suggest that our $\mathrm{CaCO}_{3}-P 2_{1} / c-h$ structure is the best available candidate for the observed high pressure phase because it has a much lower enthalpy than $C 222_{1}$.
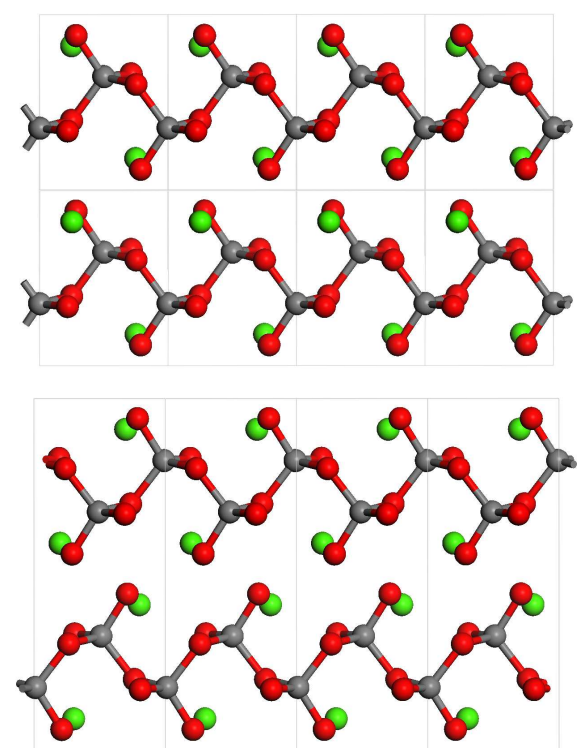

FIG. 4. (Color online) The $C 222_{1}$ (top) and $\mathrm{CaCO}_{3}-P 2_{1} / c-h$ pyroxene-type (bottom) structures of $\mathrm{CaCO}_{3}$ at $60 \mathrm{GPa}$. The $\mathrm{Ca}$ atoms are in green, carbon in grey, and oxygen in red.

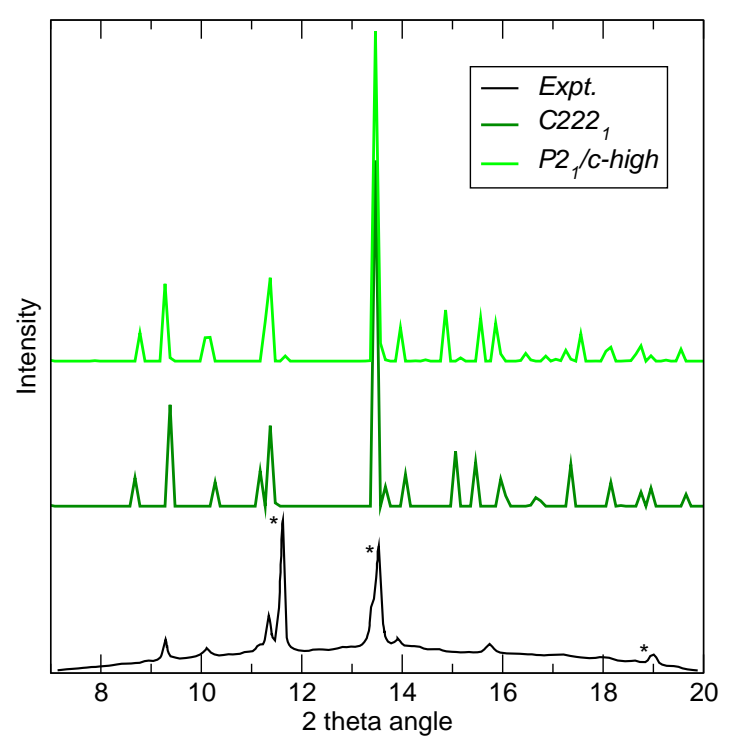

FIG. 5. (Color online) X-ray diffraction patterns of the $C 222_{1}{ }^{15}$ and $\mathrm{CaCO}_{3}-P 2_{1} / c$ - $h$ phases of $\mathrm{CaCO}_{3}$, compared with experimental data from Fig. 1(b) of Ref. 34. Data at $182 \mathrm{GPa}$ are reported, with an incident wavelength of 0.415 $\AA$. The stars indicate that the peak immediately to the right arises from platinum.

\section{CHEMICAL REACTIONS IN EARTH'S MANTLE}

We have investigated possible chemical reactions involving the mantle materials $\mathrm{CaCO}_{3}, \mathrm{MgCO}_{3}, \mathrm{CO}_{2}$, $\mathrm{MgSiO}_{3}, \mathrm{CaSiO}_{3}, \mathrm{SiO}_{2}, \mathrm{CaO}$ and $\mathrm{MgO}$, following the approach of Oganov et $a{ }^{19}{ }^{19}$. The most stable struc- 
tures of each compound at the relevant pressures are used, as provided by DFT studies. We use the $P a \overline{3}$, $\mathrm{P}_{2} / \mathrm{mnm}$, and $\mathrm{I} \overline{4} 2 d$ structures of $\mathrm{CO}_{2}{ }^{35}$, the stishovite, $\mathrm{CaCl}_{2}$ and pyrite structures of $\mathrm{SiO}_{2}{ }^{36}$, the rocksalt structure of $\mathrm{MgO}$, the perovskite and post-perovskite structures of $\mathrm{MgSiO}_{3}{ }^{37-39}$, and the orthorhombic structure of perovskite $\mathrm{CaSiO}_{3}{ }^{40}$. (We have not considered the cubic phase of $\mathrm{CaSiO}_{3}$ that is stabilized at high temperatures and pressures and is relevant in the lower mantle ${ }^{41}$.)

Decomposition of $\mathrm{CaCO}_{3}$ and $\mathrm{MgCO}_{3}$ into the alkaline earth oxides plus $\mathrm{CO}_{2}$ is found to be unfavorable. Under conditions of excess $\mathrm{SiO}_{2}$, the reaction

$$
\mathrm{MgCO}_{3}+\mathrm{SiO}_{2} \rightarrow \mathrm{MgSiO}_{3}+\mathrm{CO}_{2}
$$

is found to be energetically unfavorable up to $138 \mathrm{GPa}$, which is just above the pressure at the mantle-core boundary, see Fig. 6 . We find that the reaction

$$
\mathrm{CaCO}_{3}+\mathrm{SiO}_{2} \rightarrow \mathrm{CaSiO}_{3}+\mathrm{CO}_{2}
$$

does not occur below $200 \mathrm{GPa}$, see Fig. 7, which is much higher than the value of $135 \mathrm{GPa}$ reported in Ref. 19. We conclude that both $\mathrm{MgCO}_{3}$ and $\mathrm{CaCO}_{3}$ are stable within the Earth's mantle under conditions of excess $\mathrm{SiO}_{2}$. These results suggest that free $\mathrm{CO}_{2}$ does not occur as an equilibrium phase within the Earth's mantle.

$\mathrm{MgCO}_{3}$ has generally been believed to be the dominant carbonate throughout the Earth's mantle. This assumption can be tested when excess $\mathrm{MgO}$ is present by determining the relative stability of $\mathrm{CaCO}_{3}+\mathrm{MgO}$ and $\mathrm{MgCO}_{3}+\mathrm{CaO}$. We find that $\mathrm{CaCO}_{3}+\mathrm{MgO}$ is the more stable up to pressures of about $200 \mathrm{GPa}$, so that $\mathrm{CaCO}_{3}$ is the stable carbonate under these conditions. In the case of excess $\mathrm{MgSiO}_{3}$ we consider the reaction

$$
\mathrm{CaCO}_{3}+\mathrm{MgSiO}_{3} \rightarrow \mathrm{CaSiO}_{3}+\mathrm{MgCO}_{3},
$$

finding that $\mathrm{CaCO}_{3}$ is more stable than $\mathrm{MgCO}_{3}$ from 100 $\mathrm{GPa}$ up to pressures well above those of $136 \mathrm{GPa}$ found at the mantle-core boundary, see Fig. 8.

Finally, we consider the dependence of our results on the density functional used for the $s p$-bonded phases considered here. At high pressure the electronic charge densities increase and tend to become more uniform. The PBE functional has been extensively tested and has been used in many successful high-pressure studies. It is essentially exact in the uniform limit and it gives an excellent description of the linear response to an applied potential. The local density approximation (LDA) shares these attributes, and results obtained with the PBE and LDA functionals approach one another at high pressures. These characteristics suggest that the PBE and LDA functionals are good choices for high pressure studies. The transition pressures we have calculated are a little lower within the LDA than PBE, by about $10 \mathrm{GPa}$ for Eq. (1) and $2 \mathrm{GPa}$ for Eq. (3). This suggests that the $\mathrm{PBE}$ and LDA functionals give reasonably accurate results.

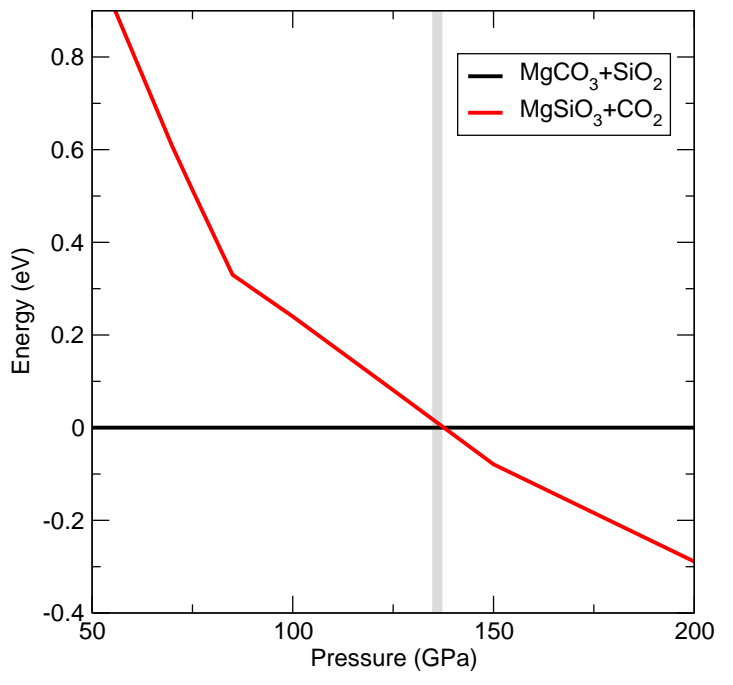

FIG. 6. (Color online). The relative stabilities per f.u. as a function of pressure of $\mathrm{MgCO}_{3}+\mathrm{SiO}_{2}$ and $\mathrm{MgSiO}_{3}+\mathrm{CO}_{2}$. The vertical gray line indicates the pressure at the base of the mantle (136 GPa). In this and the following figures, the kinks arise from phase transitions.

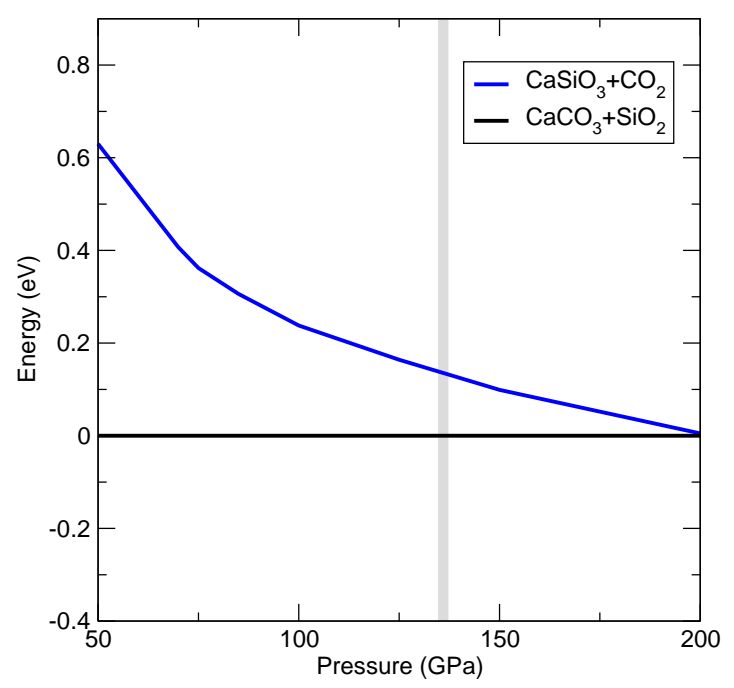

FIG. 7. (Color online). The relative stabilities per f.u. as a function of pressure of $\mathrm{CaSiO}_{3}+\mathrm{CO}_{2}$ and $\mathrm{CaCO}_{3}+\mathrm{SiO}_{2}$. The vertical gray line indicates the pressure at the base of the mantle $(136 \mathrm{GPa})$.

\section{CONCLUSIONS}

In conclusion, we have searched for structures of $\mathrm{CaCO}_{3}$ and $\mathrm{MgCO}_{3}$ at mantle pressures using $\mathrm{AIRSS}^{20,21}$. We have found a $\mathrm{CaCO}_{3}-P 2_{1} / c$-l structure with $s p^{2}$ bonded carbon atoms that is predicted to be stable within the range $32-48 \mathrm{GPa}$. We have also found a high pressure $\mathrm{CaCO}_{3}-P 2_{1} / c$ - $h$ structure with $s p^{3}$ bonded carbon atoms that is about $0.18 \mathrm{eV}$ per f.u. more stable than the $C 222_{1}$ phase proposed by Oganov et al. ${ }^{15}$. Both the $\mathrm{CaCO}_{3}-P 2_{1} / c-h$ and $C 222_{1}$ structures are compati- 


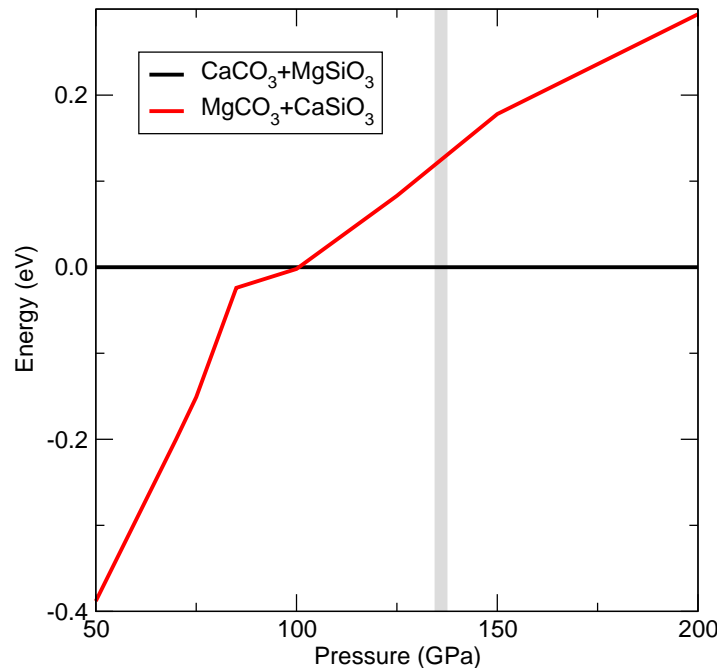

FIG. 8. (Color online) Enthalpy per f.u. of $\mathrm{CaCO}_{3}+\mathrm{MgSiO}_{3}$ compared with that of $\mathrm{CaSiO}_{3}+\mathrm{MgCO}_{3}$. Below $100 \mathrm{GPa}$ we find that $\mathrm{CaSiO}_{3}+\mathrm{MgCO}_{3}$ is the most stable, while above 100 $\mathrm{GPaCaCO} \mathrm{Ca}_{3}+\mathrm{MgSiO}_{3}$ is the most stable. ble with the available X-ray diffraction data ${ }^{34}$. However, $\mathrm{CaCO}_{3}-P 2_{1} / c-h$ is the most stable structure from $76 \mathrm{GPa}$ to pressures well above those encountered within the Earth's lower mantle ( $\leq 136 \mathrm{GPa})$. Our AIRSS calculations suggest a previously unknown phase of $\mathrm{MgCO}_{3}$ of $P \overline{1}$ symmetry that is predicted to be thermodynamically stable in the pressure range 85-101 GPa. Our results suggest that $\mathrm{CO}_{2}$ is not a thermodynamically stable compound under deep mantle conditions. Under conditions of excess $\mathrm{MgSiO}_{3}$ we find that $\mathrm{CaCO}_{3}$ is more stable than $\mathrm{MgCO}_{3}$ above $100 \mathrm{GPa}$. This result arises directly from our discovery of the highly stable $\mathrm{CaCO}_{3}-P 2_{1} / c-h$ phase.

\section{ACKNOWLEDGMENTS}

We acknowledge financial support from the Engineering and Physical Sciences Research Council (EPSRC) of the United Kingdom.
* c.pickard@ucl.ac.uk

1 B. Marty and A. Jambon, Earth Planet. Sci. Lett. 83, 16 (1987).

2 A. N. Halliday, Geochimica et Cosmochimica Acta 105, 146 (2013).

3 S. Ghosh, E. Ohtani, K. D. Litasov, and H. Terasaki, Chemical Geology 262, 17 (2009).

${ }^{4}$ M. L. Frezzotti, J. Selverstone, Z. D. Sharp, and R. Compagnoni, Nature Geoscience 4, 703 (2011).

5 http://deepcarbon.net/.

${ }^{6}$ R. Dasgupta and M. M. Hirschmann, Earth Planet. Sci. Lett. 298, 1 (2010).

7 Robert M. Hazen and Craig M. Schiffries, Reviews in Mineralogy and Geochemistry 75, 1-6 (2013).

8 W. L. Bragg, Proc. R. Soc. Lond. A 89, 468 (1914).

9 P. W. Bridgman, American Journal of Science 237, 7 (1939).

10 K. Suito, J. Namba, T. Horikawa, Y. Taniguchi, N. Dakuraos, M. Kobayashi, A. Onodera, O. Shimomura, and T. Kikegawa, Am. Mineral. 86, 997 (2001).

11 M. Merlini, M. Hanfland, and W. A. Crichton, Earth Planet. Sci. Lett. 333, 265 (2012).

12 K. Catalli and Q. Williams, Am. Mineral. 90, 1679 (2005).

13 W. L. Bragg, Proc. R. Soc. Lond. A 105, 16 (1924).

${ }^{14}$ S. Ono, T. Kikegawa, Y. Ohishi, and J. Tsuchiya, Am. Mineral. 90, 667 (2005).

15 A. R. Oganov, C. W. Glass, and S. Ono, Earth Planet. Sci. Lett. 241, 95 (2006).

16 G. Fiquet, F. Guyot, M. Kunz, J. Matas, D. Andrault, and M. Hanfland, Am. Mineral. 87, 1261 (2002).

17 M. Isshiki, T. Irifune, K. Hirose, S. Ono, Y. Ohishi, T. Watanuki, E. Nishibori, M. Takata, and M. Sakata, Nature 427, 60 (2004).

18 E. Boulard, A. Gloter, A. Corgne, D. Antonangeli, A.-L. Auzende, J.-P. Perrillat, F. Guyot, and G. Fiquet, Proc. Natl. Acad. Sci. USA 108, 5184 (2011).
19 A. R. Oganov, S. Ono, Y. Ma, C. W. Glass, and A. Garcia, Earth Planet. Sci. Lett. 273, 38 (2008).

20 C. J. Pickard and R. J. Needs, J. Phys.: Condens. Matter 23, 053201 (2011).

${ }^{21}$ C. J. Pickard and R. J. Needs, Phys. Rev. Lett. 97, 045504 (2006).

22 C. J. Pickard and R. J. Needs, Phys. Rev. B 76, 144114 (2007).

23 A. D. Fortes, E. Suard, M.-H. Lemee-Cailleau, C. J. Pickard, and R. J. Needs, J. Am. Chem. Soc. 131, 13508 (2009).

${ }^{24}$ G. I. G. Griffiths, A. D. Fortes, C. J. Pickard, and R. J. Needs, J. Chem. Phys. 136, 174512 (2012).

${ }^{25}$ L. Pauling, J. Am. Chem. Soc. 51, 1010 (1929).

${ }^{26}$ D. J. Wales, Chem. Phys. Lett. 285, 330 (1998).

27 S. J. Clark, M. D. Segall, C. J. Pickard, P. J. Hasnip, M. I. J. Probert, K. Refson, and M. C. Payne, Z. Kristallogr. 220, 567 (2005).

28 J. P. Perdew, K. Burke, and M. Ernzerhof, Phys. Rev. Lett. 77, 3865 (1996).

29 D. Vanderbilt, Phys. Rev. B 41, 7892 (1990).

30 S. Arapan, J. S. de Almeida, and R. Ahuja, Phys. Rev. Lett. 98, 268501 (2007).

31 S. Arapan and R. Ahuja, Phys. Rev. B 82, 184115 (2010).

${ }^{32}$ W. Ostwald, Zeitschrift für Physikalische Chemie 22, 289 (1897).

33 See Supplemental Material at http://link.aps.org/supplemental/.... for details of the structures.

34 S. Ono, T. Kikegawa, and Y. Ohishi, Am. Mineral. 92, 1246 (2007).

35 C. Lu, M. Miao, and Y. Ma, J. Am. Chem. Soc. 135, 14167-14171 (2013).

36 B. B. Karki, M. C. Warren, L. Stixrude, G. J. Ackland, and J. Crain, Phys. Rev. B 55, 3465-3471 (1997). 
37 M. Murakami, K. Hirose, K. Kawamura, N. Sata, and Y. Ohishi, Science 304, 855-858 (2004).

38 A. R. Oganov and S. Ono, Nature 430, 445448 (2004).
39 T. Tsuchiya, J. Tsuchiya, K. Umemoto, and R. M. Wentzcovitch, Earth Planet. Sci. Lett. 224, 241-248 (2004).

40 B. Magyari-Kope, L. Vitos, G. Grimvall, B. Johansson, and J. Kollar, Phys. Rev. B 65, 193107 (2002).

41 T. Sun, D.-B. Zhang, and R. M. Wentzcovitch, Phys. Rev. B 89, 094109 (2014). 